\title{
Elektrikli Araçlar ile Klasik İçten Yanmalı Motorlu Araçların Çeşitli Yönlerden Karşılaştırılması
}

\author{
Yusuf GÜRBÜZ ${ }^{1 *}$, A. Afşin KULAKSIZ ${ }^{2}$ \\ ${ }^{1}$ Necmettin Erbakan Üniversitesi, Seydişehir Meslek Yüksek Okulu, Elektronik ve Otomasyon Bölümü, Konya, Türkiye \\ ${ }^{2}$ Selçuk Üniversitesi, Mühendislik Fakültesi, Elektrik-Elektronik Mühendisliği, Konya, Türkiye
}

Geliș tarihi/Received 14.03.2016

Düzeltilerek geliş tarihi/Received in revised form 02.07.2016

Kabul tarihi/Accepted 11.07.2016

$\ddot{O} z$

Günümüzde dünya enerji ihtiyacı büyük oranda fosil yakattan karşılanmakta ve bu enerjinin \%26'sl ulaşımda kullanılmaktadır. Bu enerji kullanımına bağlı olarak kara yollarında \%26 $\mathrm{CO}_{2}$ emisyonu oluşmaktadır. Avrupa Birliği, 2020 yll için tüm sera gazı emisyonlarını, 1990 yll seviyesine göre $\% 20$ oranında azaltmayı hedeflemektedir. Bu hedefe ulaşmada, özellikle $\mathrm{CO}_{2}$ emisyonu ve yakıt tüketimi, geleneksel içten yanmal motorlu araçlara göre büyük avantajlara sahip olan elektrikli araçlar aday gösterilmektedir. Gelişen teknoloji sayesinde otomobil dünyasinda da önemli değiş̧iklikler yapılmaya çalışılmaktadır. Otomobillerde çok uzun süredir kullanılan içten yanmalı motorların yerine elektrikli motorlar kullanılarak elektrikli araçlar üretilmektedir. Bu çalışmada, elektrik motoruna sahip elektrikli araçlar ile içten yanmalı motora sahip klasik araçlar çeşitli yönlerden karşılaştırılmıştır. Batarya, elektrik motoru ve kontrol kartı olmak üzere ü̧ ana bileşenden oluşan elektrikli araçlar, çok daha fazla hareketli parçaya sahip olan klasik içten yanmalı motorlu araçlara göre daha basit, daha kompakt ve daha güvenli olmaktadırlar. Ayrıca, elektrikli araçların verimi içten yanmalı motorlu araçlara göre daha yüksektir ve yaklaşılk üç kattır. Buna karşın, elektrikli araçların tam dolu bataryalar ile gidebildiği mesafe, yakıt deposu tam dolu olan içten yanmal motorlu araçların gidebildiği mesafeye göre çok düşüktür ve bu oran yaklaşı k dörtte birdir. Ayrıca bataryaların şarj olma süresi, bir depo yakitın dolma süresine oranla daha fazladır ve şarj istasyon sayısl, yaklt istasyon sayısina göre çok azdır. Bu olumsuzluklar, elektrikli araçların yukarıda sayılan avantajlarını gölgede bırakmaktır. Dolayısıyla, elektrikli araçlar, içten yanmalı motorlu araçlara göre daha az tercih edilmektedirler.

Anahtar kelimeler: Elektrikli Araç, Elektrik Motoru, İçten Yanmalı Motor, Karşılaştırma

\section{Comparison of Conventional Internal-Combustion Engine Vehicle and Electric Vehicles in Various Aspects}

\begin{abstract}
Nowadays, the energy needs of the world are mostly met by fossil fuels and $26 \%$ of this energy is consumed in transportation. Depending on this energy consumption in highway transportation, $\mathrm{CO}_{2}$ emission accounts $26 \%$ of the total. For 2020, Europe Union projects a reduction of overall greenhouse emissions below 1990 levels. Compared with internal-combustion engine (ICE) vehicles, the superiorities of electric vehicles (EVs) in regard to their $\mathrm{CO}_{2}$ emission and fuel consumption, they are a viable option to reach these levels. By means of the developing technology, crucial changes are being made in automotive industry. In automobiles, internal-combustion engines that have been used for a long time are being replaced by electric motors and EVs are
\end{abstract}

\footnotetext{
*Yusuf GÜRBÜZ, ygurbuz@konya.edu.tr, Tel: (332) 58254 54-144
} 
being produced. In this study, EVs powered by electric motors and conventional vehicles with internal combustion engine have been compared in various aspects. EVs, consisting of three major units namely battery, electric motor and control board, are simpler, more compact and safer than conventional ICE vehicles that have many more moving parts. Furthermore, the efficiency of EVs is higher than ICE vehicles and they are approximately three times more efficient. However, the range of EVs with fully charged batteries is much less than the range of ICE vehicles with a full fuel tank. The ratio is approximately one quarter. Also, the charge times of batteries are much longer than filling a fuel tank and the number of charge stations is much less than the number of fuel stations. These negative aspects overshadow the explained advantages. Therefore, EVs are currently preferred less than ICE vehicles.

Keywords: Electric Vehicle, Electric Motor, Internal Combustion Engine, Comparison.

\section{Giriş}

Araç teknolojisinde elektrikle tahrik sistemleri ilk çalışılan konular olmasına rağmen içten yanmalı motorların icat edilmesi ve elektrikli araçların batarya kapasitelerinin düşük olmasından dolayı elektrikli araçlar uzun yıllar ilgi görmemiştir. Günümüzde dünya enerji gereksinimi büyük oranda fosil yakıtlarla karşılanmaktadır. Ancak fosil yakıtların yakın gelecekte tükenecek olması ve yanmadan sonra açığa çıkardığ 1 zararlı gazların atmosferdeki miktarının artmasından dolayı ozon tabakası zarar görmekte ve sera etkisi oluşmaktadır. $\mathrm{Bu}$ durum son zamanlarda artan çevresel kaygilarla fosil yakıt kullanımına karşı insanları harekete geçirmiştir (Mazman vd., 2012). Şekil 1'de görüldüğü gibi dünyadaki enerjinin \%26's1 ulaşımda kullanılmakta ve bu kullanıma bağlı olarak \%26 $\quad \mathrm{CO}_{2}$ emisyonu oluşmaktadır (Anonim, 2011).

Uluslararası alanda, sera gazı emisyonlarını azaltmak için yoğun çalışmalar yapılmaktadır. Avrupa Birliği (AB) 2020 yılı için tüm sera gazı emisyonlarını 1990 seviyesine göre \%20 oranında azaltmak istemektedir. $\mathrm{Bu}$ hedeflerine uygun olarak, 2012 yilından itibaren klasik içten yanmalı motor teknolojilerinin geliştirilmesiyle kilometre başına $\mathrm{CO}_{2}$ miktarına $130 \mathrm{~g}$, alternatif yöntemler kullanılarak kilometre başına $\mathrm{CO}_{2}$ miktarına $120 \mathrm{~g}$ sınırı getirilmiştir. 2020 yılında araçlarda kilometre başına $\mathrm{CO}_{2}$ miktar1 95g olarak hedeflenmektedir. $\mathrm{Bu}$ durum 443/2009 sayılı AB Regülasyonunda belirlenmiştir. Karayolu ulaşımında motorlu taşıt araçlarında kullanılan fosil yakıtlardan kaynaklanan sera gazı emisyonlarının azaltılması, araçlarda daha düşük emisyon sağlayan alternatif tahrik sistemlerinin kullanımlarını gündeme getirmiştir (Anonim, 2010).

Batarya teknolojisindeki yenilikler sayesinde kurşun-asit bataryalar yerini birim ağırlık başına daha verimli ve daha kapasiteli olan lityum bataryalara, motor ve kontrol teknolojilerindeki gelişmeler sayesinde ise firçalı DC motorlar yerini ya firçasız DC motorlara ya da indüksiyon motorlara bırakmışlardır. $\mathrm{Bu}$ gelişmelerle birlikte otomobil dünyasında da çok büyük değişiklikler yapılmaya çalışılmaktadır. Otomobillerde çok uzun süredir kullanılan içten yanmalı motorların yerine elektrik motorları kullanılarak ya tamamen elektrikli ya da hibrid araçlar üretilmektedir. Hibrid araçlar, klasik içten yanmalı motor ve elektrik motorunun birlikte tahrik amaçlı kullanıldığı araçlardır. Aracın üzerindeki bataryalarda depolanan elektrik enerjisi ile elektrik motoru kullanılarak, hem $\mathrm{CO}_{2}$ emisyonu hem de yakıt tüketimi açısından geleneksel içten yanmalı motorlu araçlara göre büyük avantajlar sağlamaktadır (Uçarol ve Kural, 2009). Elektrikli araçların $\mathrm{CO}_{2}$ emisyon miktarı, elektriğin elde edildiği yere bağlı olarak çok düşük ya da sıfır olmaktadır. Örneğin elektrikli araç elektrik ihtiyacını yenilenebilir enerjiden karşılarsa sıfır emisyona sahip olabilmektedir. 

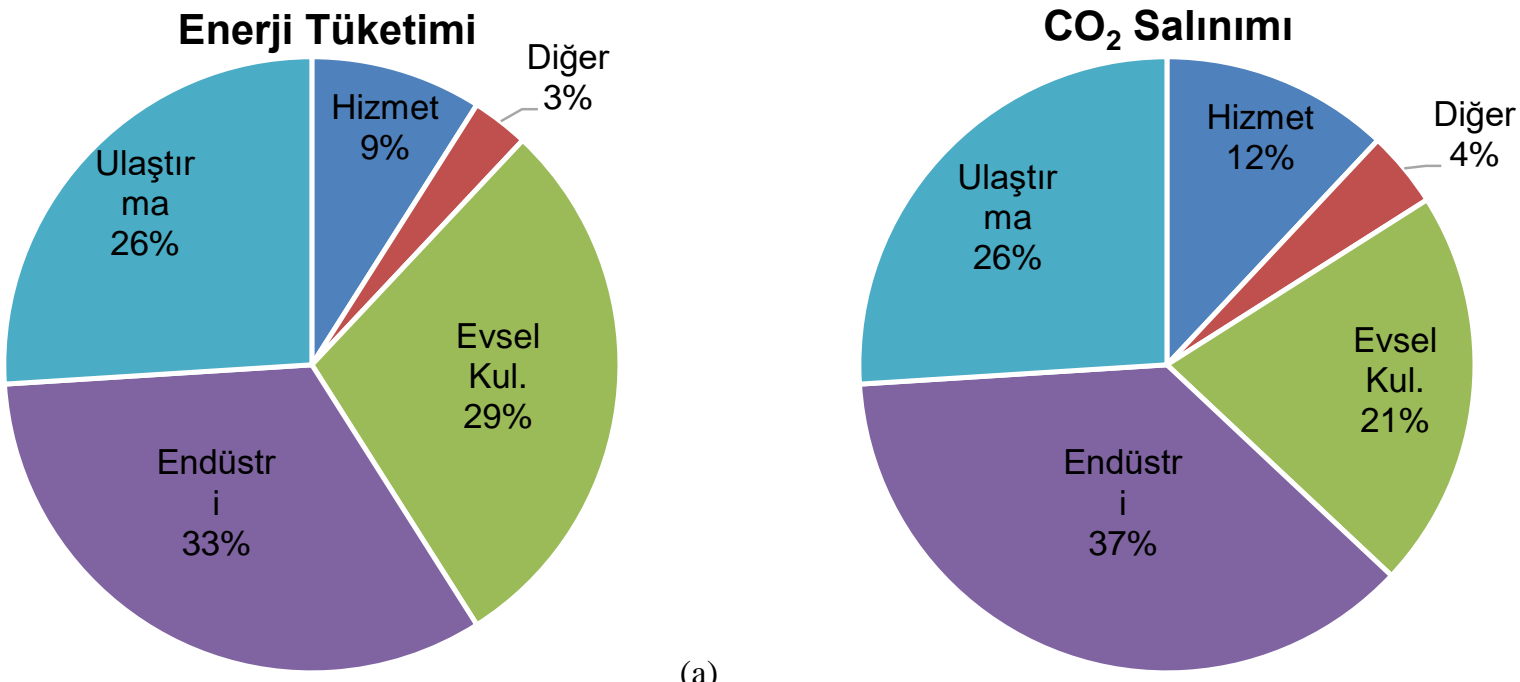

(b)

Şekil 1. a) Sektörlere göre dünya enerji tüketimi, b) enerji tüketimine bağlı olarak $\mathrm{CO}_{2}$ emisyonu

$\mathrm{Bu}$ duruma ilaveten elektrikli araçlar her ne kadar basit yapıları, güvenirliği ve yüksek verime sahip olması gibi avantajlardan dolayı tercih sebebi olsa da bataryaların uzun sürede şarj olması, yeterli şarj istasyonlarının olmaması ve tam dolu bataryalar ile gidebileceği mesafenin düşük olmasından dolayı istenildiği kadar yaygınlaşamamaktadır. Otomotiv pazarında geleneksel içten yanmalı motorlu araçların sayısı, hibrid ve elektrikli araçların sayısından çok daha fazladır. 2009 yılında Almanya'da yapılan bir çalışmaya göre 3.8 milyon adet üretilen yeni araçların sadece 162'sinin elektrikli araç olduğu belirtilmiştir. Bu çalışmaya ilaveten ülkemizde 2012 yılı içerisinde 184, Mart 2013'e kadar ise 16 olmak üzere toplamda 200 elektrikli araç satılmıştır. Bu konuda yayınlanan istatistiki bir veri olmamasına rağmen 2015 y1lı itibariyle piyasada elektrikli araç sayısının 450-500 arasında olduğu tahmin edilmektedir. Ancak neredeyse bütün büyük otomotiv firmalarının elektrikli araçlara ilgi göstermekte olduğu ve geliştirmek için çaba sarf ettiği belirtilmektedir (Bitar ve Jabi, 2014, Polat vd., 2015). $\mathrm{Bu}$ firmaların çabaları ve teknolojinin ilerlemesiyle elektrik motorları ile kontrol üniteleri daha verimli ve bataryalar birim ağırlık başına daha kapasiteli hale getirilerek, elektrikli araçların tek şarjla daha uzun mesafe almaları sağlanabilecektir. Dolayısıyla, elektrikli araçlar içten yanmalı motorlu araçlarla rekabet edebilir hale gelebilecektir. Tüm tahminler yakın gelecekte bu araçların pazar paylarının artacağını göstermektedir.

Bir elektrikli araç temel olarak elektrik motoru, kontrol ünitesi ve batarya grubundan oluşmaktadır. Şekil 2'de elektrikli aracın prensip şeması görülmektedir.

Bu üç parça elektrikli araç için çok önemlidir. Örneğin bataryaların birim ağırlık başına daha çok enerji depo edebilmesi, elektrik motorunun ve kontrol ünitesinin daha verimli olması ile elektrikli araç tek şarj ile daha fazla mesafe alabileceği anlamına gelmektedir. Dolayısıyla, basit yapıda, sessiz, performansl1, vites kutusuna ihtiyaç duymaması gibi önemli avantajlarından dolayı tercih sebebi olan elektrikli araçların en büyük engeli olan tek şarj ile k1sa mesafede gitme problemi çözülerek içten yanmalı motorlara göre daha çok tercih edilmesi ve zamanla onun yerine geçmesi sağlanabilir. 


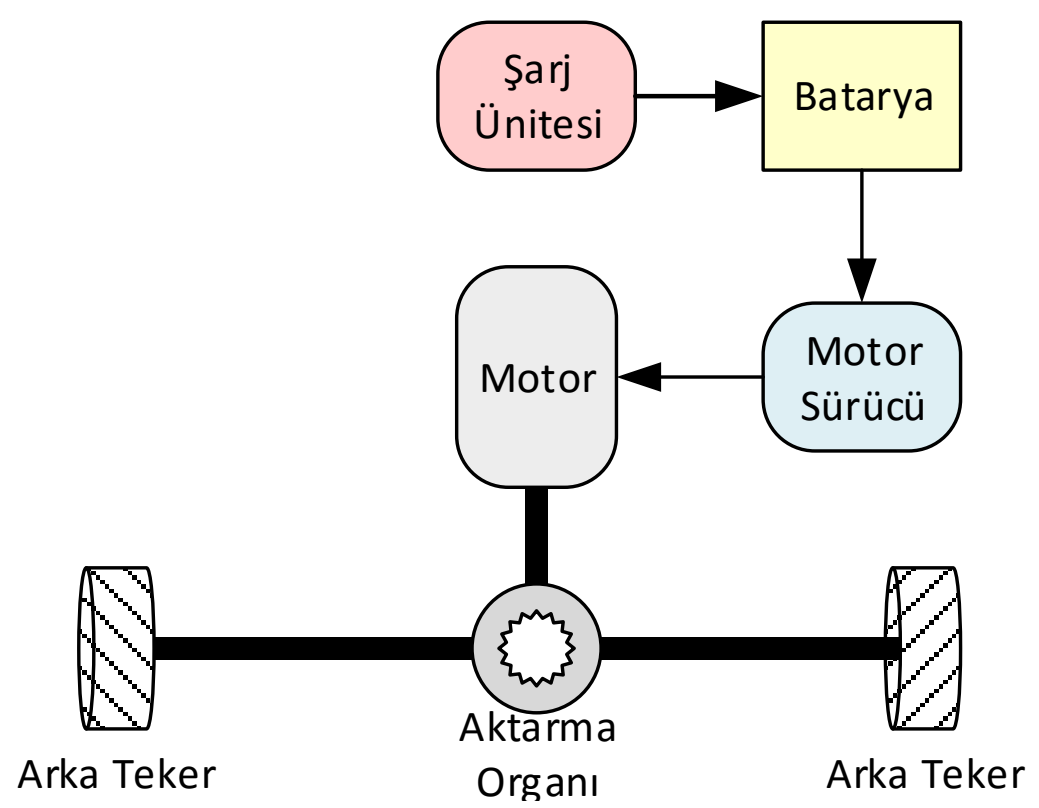

Şekil 2. Elektrikli aracın prensip şeması

\section{2. İçten Yanmalı Motorlar ile Elektrik Motorlarının Karşılaştırılması}

Araçlarda tahrik sistemi olarak geçmişten günümüze içten yanmalı motorlar uzun süredir yaygın olarak kullanılmaktadır. İçten yanmalı motor karmaşı, şaşırtıcı bir makinedir. Kusursuz uyum içerisinde valfler açılır-kapanır, kıvılcım ateşler, piston hareket eder ve krank mili döner. Krank mili pistonun doğrusal hareketini dönme hareketine dönüştürerek aracın hareket etmesini sağlar. Ancak içten yanmalı motorun bu karmaşıklığından dolayı verimi düşüktür. En iyi ihtimalle yakıt enerjisinin sadece \%30 'u hareket enerjisine dönüştürülür ve motor dönmediği zaman moment elde edilemez. Buna karşın elektrik motorları çok basit yapıya sahiptirler. Motor elektrik enerjisini mekanik güce çevirir. Aynı zamanda bir generatör olarak da mekanik gücü elektriğe dönüştürebilir. İçten yanmalı motorda olduğu gibi çok fazla parçaya sahip değildir, hareketli parça olarak sadece rotora sahiptir. Doğrusal hareketi dairesel harekete dönüştürmeye gerek yoktur ve mekaniksel zamanlamaya da ihtiyaç duymazlar (URL-1, 2007). Elektrikli aracın sürüş performansını daha iyi anlayabilmek için çalışma ve bekleme performans1, gürültü ve titreşim, vites değiştirme, verim gibi bazı kriterlere göre geleneksel içten yanmalı motora sahip araçlar ile karşılaştırılması yapılmıştır.

\section{1. Çalışma ve Boşta Bekleme Performansı}

Geleneksel içten yanmalı motorlarda aracı çalıştırmak için marş motoru krank milini yaklaşık 200-250 d/d'de döndürür. Bu esnada yakıt enjeksiyonu başlar ve krank mili 800 $850 \mathrm{~d} / \mathrm{d}$ boşta bekleme hızına ulaşır. Motor boșta bekleme hızına ulaştı̆̆ 1 anda hareket etmek için hazırdır.

Elektrikli araç krank milinin hareket ettirilmesine ve boşta beklemeye ihtiyaç duymaz. Elektrik motoru ile herhangi bir devirde anlık moment elde edilebilir. Gaz pedalına basıldığ 1 anda motorun tam dönme gücü elde edilir. İçten yanmalı motorlu araç verimini artırmak ve emisyonu azaltmak için başlatma/durdurma kontrolüne ihtiyaç duyarken elektrikli araçta böyle bir kontrole gerek yoktur (Guzzella ve Onder, 2010).

\subsection{Gürültü̈ ve Moment Dalgalanması}

İçten yanmalı motor gürültü ve titreşimlerin temel kaynağı olan yüksek moment dalgalanmalarına sahiptir. İçten yanmalı 
motorda moment üretimi sürekli değildir. Moment üretimini sürekli hale getirmek ve krank miline denge etkisini sağlamak için içten yanmalı motor ile aktarma arasına volan eklenir. Volan, vites geçişi esnasında oluşan moment boşluklarını minimuma düşürmektedir.

İndüksiyon motoru veya kalıcı mıknatıslı senkron motor gibi elektrik motorlarında moment dalgalanması makinanın tasarımı ve kontrol metotları ile minimum seviyeye indirilebilir. $\mathrm{Bu}$ elektrik motorları içten yanmalı motorun aksine mekaniksel gürültüye ve titreşim problemlerine sahip değillerdir.
Hatta elektrikli araçlar o kadar sessizdir ki isteğe bağlı olarak araca yapay ses çıkaran ekipmanlar eklenmektedir (Karamuk, 2011).

\subsection{Moment Aralı̆̆ı ve Vites Değiştirme Gereksinimi}

İçten yanmalı motor maksimum momente çok yüksek devirlerde ulaşmaktadır. Ancak motor maksimum momente ulaştığı anda hızı çabucak düşmeye başlar. Bu sınırlı moment aralığ 1 problemi, farklı vites dişli oranları ile giderilmeye çalışılmaktadır. Şekil 3'te içten yanmalı motor ile elektrik motorun momenthız karakteristiği verilmiştir (URL-1, 2007).

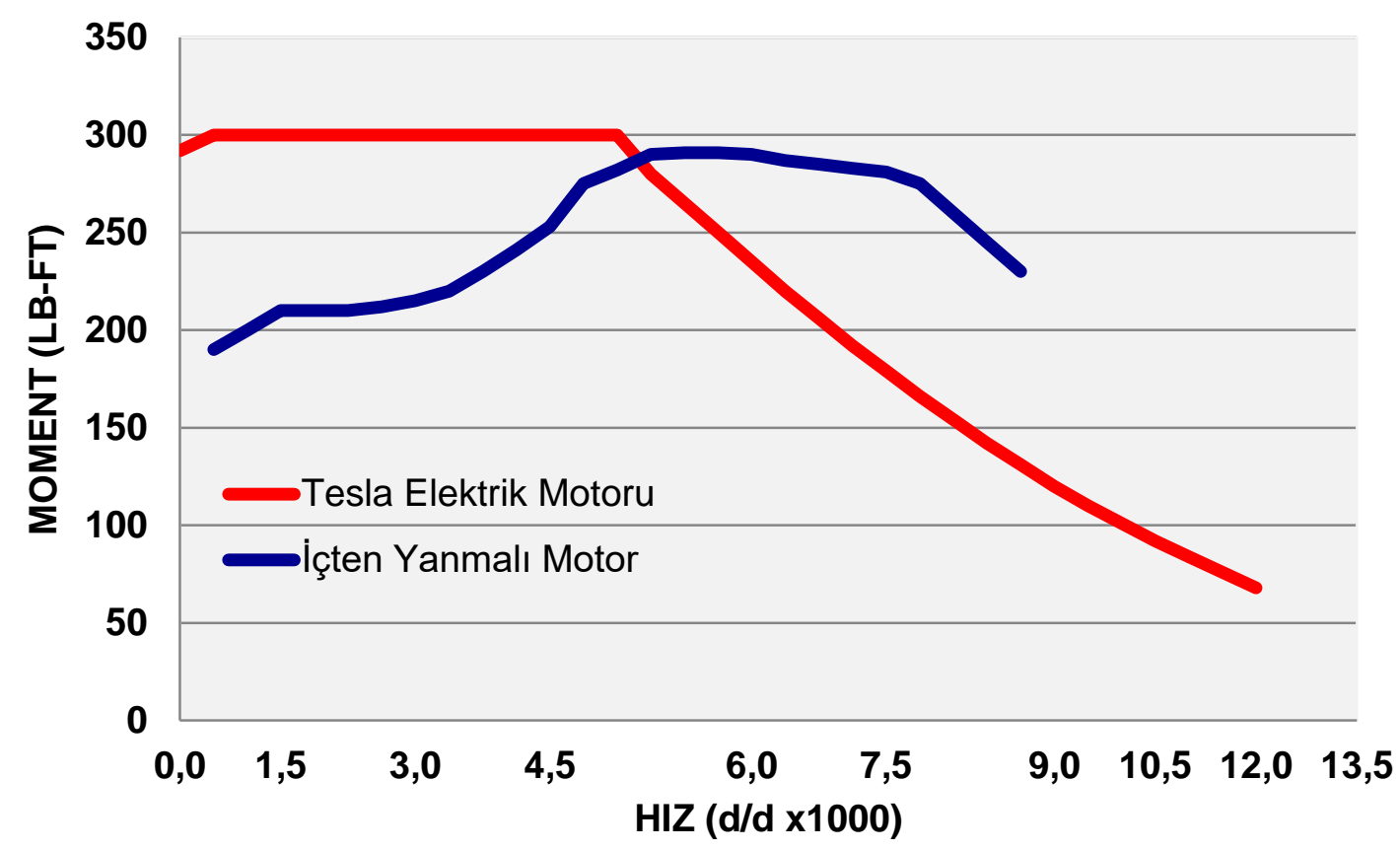

Şekil 3. İçten yanmalı motor ve elektrik motorunun moment-hız karakteristiği

İçten yanmalı motorun güç çıkışı daha hızlı oran ile geliştirilebilirdi. Ancak, bu motorların devir hiz1 sinırları $5000-6000 \quad \mathrm{~d} / \mathrm{d}$ civarındadır. Motorun devir hızı bu değerleri geçtiğinde motorun parçalarını bir arada tutmak ve motorun zamanlamasını ayarlamak maliyetli olmaktadır. Örneğin, kapanan valfleri iten yaylar düşünülürse, motorun devri artarken yaylar valfi açmaya yetişemeyebilir ve valfin pistona çarpması ile çok olumsuz motor arızası meydana gelebilir.

Bir elektrik motoru ile herhangi bir devirde anlık moment elde edilebilir. Gaz pedalına basıldığı anda motorun tam dönme gücü elde edilebilmektedir. Maksimum moment neredeyse dakikada $6000 \mathrm{~d}$ /d'ya kadar sabit kalmakta ve daha sonra yavaşça düşmeye başlamaktadır. Özellikle düşük devirlerde elde edilen bu geniş moment aralığı vites değiştirme ihtiyacını ortadan kaldırmaktadır. Bu yüzden elektrikli araç büyük çoğunlukla tek vitesli olmaktadır. Yani sifirdan maksimum hıza kadar tek vites kullanmaktadir. Aracın geri gitmesi motorun ters yönde çalıştırılmasıyla gerçekleştirilebilmektedir. Dolayısıyla, elektrikli araçlarda geri vitese ihtiyaç olmamaktadır. Bu tasarım 
elektrikli araçları hem inanılmaz basit, güvenilir ve kompakt yapmakta, hem de sürüş keyfini büyük ölçüde artırmaktadır (URL-1, 2007).

\subsection{Bakım Gereksinimi}

Elektrikli bir otomobilin çalışma masraflarının çoğu batarya bakımıdır. Çünkü elektrikli bir aracin motorunda sadece beş hareketli parça varken, içten yanmalı motoru sahip araçta yüzlerce parça bulunmaktadır. Elektrikli otomobiller değiștirilmesi gereken pahalı bataryalara sahiptirler fakat bunun dışında özellikle yaygın lityum tabanlı tasarımlarda çok düşük bakım masrafları bulunmaktadır. Tesla Roadster'ın çok büyük bataryalarının sıradan bir sürüş ile yedi yıl dayanması tahmin edilmektedir ve bugün satın alındığında $12.000 \$$ mal olmaktadır. 64 km'lik günlük kullanım yedi yılda 164.500 $\mathrm{km}$ ile $1 \mathrm{~km}$ 'de $0.0729 \$$ batarya kullanım masrafına veya $64 \mathrm{~km}$ 'de $4.70 \$$ 'a denk gelmektedir. Ancak zamanla bunun miktarın düşeceği tahmin edilmektedir (URL-2, 2015). Buna karşın içten yanmalı motora sahip araçların bakımı, üretici firmaların belirlediği zamanlarda genelde 1 yıl veya belirlediği periyotlarda 10.000/15.000, 20.000/30.000, $30.000 / 45.000 \mathrm{~km}$ 'lerde yapilmaktadır. $\mathrm{Bu}$ bakım periyotlarında araçlardaki sıvıların, filtrelerin, ayarların ve mekanik parçaların bakımları, kontrolleri ve değişimleri yapılmaktadır. İlk $10000 / 15000$ km'de aracın genellikle hava filtresi, yă filtresi, yakıt filtresi, polen filtresi ve motor yaği değiştirilmektedir. İkinci 20000, $30000 \mathrm{~km}$ ve katlarındaki periyotlarda araçlara ilk bakımda yapılan bakımlar ve kontrollere ilave olarak bujilerin değişimi (benzinli araçlar için), egzoz gazı dumanının kontrolü, firma talimatları doğrultusunda V kayışı kontrolü/değişimi gibi işlemler yapılır. Firmalara göre değişiklik göstermekle beraber genelde $(2-3 \mathrm{y} 1 \mathrm{l})$ veya $60000 \mathrm{~km}$ ve katlarındaki bakımlarda, debriyaj baskı ve balatasının, bazı markalarda belirli modeller için kavrama ve vites kutusu veya otomatik vites kutusu yağ ve filtresinin değişimi önerilmektedir. Ayrıca firmalar (4-5 yıl) veya $90000 / 120000 \quad \mathrm{~km}$ ve katlarındaki bakımlarında araç, triger kayışı/zinciri ve gergi rulmanlarının, vites kutusu yağının değişimini önermektedirler (MEGEP, 2011).

\subsection{Verim ve Enerji Depolama}

Bir dizel aracın optimum verimi yaklaşık $\% 32$ olmasına karşın kalıcı mıknatıslı senkron motorun verimi yaklaşık \%95 olmaktadır. Tesla firması, Tesla'nın elektrik motoru sadece yüksek güçte moment üretmekle kalmadığını aynı zamanda çok yüksek verimliliğe de sahip olduğunu ve Tesla firmasına ait elektrikli aracın bütün sürüş verimliliğinin $\% 88$ olduğunu belirtmektedir. Yani, bu durum geleneksel araçlara göre neredeyse 3 kat daha verimli olduğu anlamına gelmektedir. Elektrik motoru hem motor olarak hem de generatör olarak çalışabilmekte ve bataryaları şarj edebilmektedir. Gaz pedalı bırakıldığı anda, motor genaratör moduna geçmekte ve araç yavaşlarken bataryalar şarj edilebilmektedir. $\mathrm{Bu}$ durum geleneksel araçlardaki motor frenlemeye benzer ancak bu çok daha fazla sezgisel olmaktadır (URL-1, 2007, Karamuk, 2011).

Bununla beraber bataryaların enerji yoğunluğu elektrikli araçların sürüş menzili için çok önemli olmaktadır. Li-on bataryanın enerji yoğunluğu yaklaşık 110-160 Wh/kg olmaktadır (Burke, 2007). Elektrikli araçlarda kullanılan bataryalar $20-40 \mathrm{kWh}$ arasinda kapasitelerde değişmektedir. Ancak 38 litre benzin 360kWh'lik enerji içermektedir (Shiau vd., 2009). 38 litrelik benzinin içerdiği enerji bataryalar ile sağlanacak olursa ve batarya enerji yoğunluğu $160 \mathrm{Wh} / \mathrm{kg}$ alınacak olursa bataryaların yaklaşı ağırlığı $2.250 \mathrm{~kg}$ olacaktır. $\mathrm{Bu}$ ağırlık 38 litre benzinin ağırlığına göre çok yüksek olmaktadır. Her ne kadar elektrikli araçlar içten yanmalı motora sahip araçlara göre 3 kat verimli olmuş olsa da bataryaların birim ağırlık başına enerji yoğunluklarının sıv1 yakıtların enerji yoğunluğuna göre çok düşük olması elektrikli araçlar için halen en büyük dezavantajdır.

\section{6. Şarj ve Yakıt İstasyonu}

Polat vd. (2015) yılında yapmış oldukları çalışmada şarj istasyonu satan ve kuran firmaların şarj haritalarından yararlanmışlar 
ve firmalarla görüşmeler yapmışlardır. Yapmış oldukları görüşmeler sonucunda İstanbul Avrupa Yakası ve diğer bölgeler olmak üzere şarj istasyonu dağılımı çıkartmışlardır. Tablo 1'de elektrikli araç şarj istasyon dağılımı görülmektedir (Polat vd., 2015).

Tablo 1. Elektrikli araç şarj istasyon dağılımı

\begin{tabular}{|c|c|c|c|c|c|c|}
\hline \multirow{2}{*}{ Yerleşim } & \multicolumn{2}{|c|}{$\mathrm{AC}[\mathrm{kVA}]$} & \multicolumn{3}{|c|}{ DC $[k W]$} & \multirow{2}{*}{ Toplam } \\
\hline & 3,7 & 11 & 22 & 12 & 45 & \\
\hline İstanbul Avrupa Yakas & 24 & 4 & 88 & 47 & 4 & 167 \\
\hline Diğer Bölgeler & 31 & 3 & 135 & 56 & 2 & 227 \\
\hline Dağılımı Bilinmeyen & 400 & 0 & 0 & 0 & 0 & 400 \\
\hline Toplam & 455 & 7 & 223 & 103 & 6 & 794 \\
\hline
\end{tabular}

Tablo 1'den de görüldüğü gibi ülkemizde yaklaşık 800 adet elektrikli araç şarj istasyonu bulunmaktadır. Buna karşın ülkemizde yaklaşı 13.000 akaryakıt istasyonu ve yaklaşık 10.000 LPG istasyonu bulunmaktadır
(Erdil, 2013, URL-3, 2015). Tablo 2'de Türkiye'de bulunan akaryakıt ve LPG istasyon sayılarının yıllara göre dağılımı verilmiştir (PETDER, 2014).

Tablo 2. Akaryakıt ve LPG istasyon sayısının 2010-2014 yıllarına göre dağılımı

\begin{tabular}{|l|r|r|r|r|r|}
\hline & \multicolumn{1}{|c|}{$\mathbf{2 0 1 0}$} & \multicolumn{1}{c|}{$\mathbf{2 0 1 1}$} & \multicolumn{1}{c|}{$\mathbf{2 0 1 2}$} & \multicolumn{1}{c|}{$\mathbf{2 0 1 3}$} & \multicolumn{1}{c|}{$\mathbf{2 0 1 4}$} \\
\hline Akaryakıt İstasyonu & 12.894 & 12.348 & 12.460 & 12.623 & 12.667 \\
\hline Dağıtıcı Lisansı & 53 & 50 & 58 & 77 & 78 \\
\hline LPG İstasyonu & 8.721 & 9.377 & 9.802 & 10.089 & 10.360 \\
\hline LPG Dağıtıcı Lisansı & 64 & 70 & 72 & 73 & 79 \\
\hline
\end{tabular}

$\mathrm{Bu}$ verilere göre şarj istasyon sayısının akaryakıt istasyon sayısına göre çok düşük olduğu görülmektedir. Bunu etkileyen en büyük etken elektrikli araç sayısının içten yanmalı motora sahip araçlara göre çok az sayıda olmasidır.

\subsection{Piyasada Bulunan Araç Sayılart}

Otomotiv Dağıtıcıları Derneği (ODD)'nin istatistiklerine göre Türkiye'de 2013 Aralık sonu itibari ile yaklaşı 665 bin adet, 2014 Aralık sonu itibari ile yaklaşık 587 bin ve 2015 Aralık sonu itibari ile yaklaşık 726 bin klasik içten yanmalı motora sahip otomobil satılmıştır. Buna karşın 2013, 2014 ve 2015 Aralık sonunda sirasiyla, 31, 47 ve 120 adet elektrikli otomobil satılmıştır. Tablo 3'de y1llara göre Türkiye'de satılan otomobil sayıları gösterilmiştir (ODD 2014, 2015).
Tablo 3'den de görüldüğü gibi piyasada bulunan otomobillerin büyük çoğunluğunu içten yanmalı motora sahip araçlar oluşturmaktadır. Ancak piyasada bulunan elektrikli otomobillerin sayıları yıllara göre artmaktadir.

\section{Sonuçlar}

Bu çalışmada elektrikli araçların, klasik içten yanmalı motorlu araçlara göre çalışma ve bekleme performansında, gürültü ve titreşimde, vites değiştirmede, verim ve sürüş keyfi gibi birçok yönlerden üstün olduğu görülmüştür. Özellikle $\mathrm{CO}_{2}$ emisyonu ve yakıt tüketimi açısından geleneksel içten yanmalı motorlu araçlara göre büyük avantajlar sağlamaktadır. Öyle ki karayollarındaki $\mathrm{CO}_{2}$ emisyon miktarını azaltmak için elektrikli araçlar en büyük aday olarak görülmektedir. 
Tablo 3. 2013-2015 yılları arasında Türkiye'de satılan otomobil sayıları

\begin{tabular}{|c|c|c|c|c|}
\hline Motor Hacmi & Motor Cinsi & 2013 & 2014 & 2015 \\
\hline$\leq 1600 \mathrm{cc}$ & Benzin / Dizel & 626.047 & 558.995 & 696.076 \\
\hline $1601 \mathrm{cc} \leq 2000 \mathrm{cc}$ & Benzin / Dizel & 32.609 & 22.536 & 23.108 \\
\hline$\geq 2001 \mathrm{cc}$ & Benzin / Dizel & 5.968 & 5.753 & 6.292 \\
\hline$\leq 85 \mathrm{~kW}$ & Elektrikli & 31 & 22 & 38 \\
\hline $86 \mathrm{~kW} \leq 120 \mathrm{~kW}$ & Elektrikli & 0 & 0 & 0 \\
\hline$\geq 121 \mathrm{~kW}$ & Elektrikli & 0 & 25 & 82 \\
\hline \multicolumn{2}{|c|}{ Toplam } & 664.655 & $\mathbf{5 8 7 . 3 3 1}$ & 725.596 \\
\hline
\end{tabular}

Ayrıca elektrikli araçlar basit yapıları, güvenirliği ve yüksek verime sahip olmalarından dolayı klasik içten yanmalı motorlu araçlara göre önemli avantaja sahiptirler. Ancak, elektrikli araçların bataryalarının uzun sürede şarj olması, yeterli şarj istasyonlarının olmaması ve tam dolu bataryalar ile yeteri kadar uzun mesafe gidememeleri içten yanmalı motorlu araçlara göre en büyük dezavantajlarıdır. Dolayısıyla, batarya alanında yapılacak olan çalışmalar ile daha verimli ve daha uygun maliyetli bataryalar tasarlanarak elektrikli araçların yaygınlaşmasına büyük katkı sağlanabilir. Ayrıca, elektrikli araçların en önemli parçalarından olan elektrik motoru ve sürücüleri üzerine yapılacak yenilikçi çalışmalar sayesinde bataryaların daha verimli kullanılması sağlanarak elektrikli araçların en büyük problemi olan tek şarjla gidebildikleri kısa mesafenin uzatılması sağlanabilir.

\section{Kaynaklar}

Anonim, 2010. Elektrikli Araç Çalışma Grubu Raporu: 1-16.

Anonim, 2011. Elektrikli Araçlar İçin Enerji Depolama Çözümleri, III. Enerji Verimliği Kongresi. Gebze, TÜBİTAK MAM: 1-33.

Bitar, Z. ve Jabi, S.A., 2014. Studying the Performances of Induction Motor Used in Electric Car, Energy Procedia, 50, 342-51.
Burke, A.F., 2007. Batteries and Ultracapacitors for Electric, Hybrid, and Fuel Cell Vehicles, Proceedings of the IEEE, 95, 4, 806-20.

Erdil, M., (2013, ). Türkiye 'istasyon' çöplügüü olacak, http://www.hurriyet.com.tr/turkiyeistasyon-coplugu-olacak-22878516. 13 Mart 2016.

Guzzella, L., ve Onder, C., 2010. Introduction to Modeling and Control of Internal Combustion Engine Systems, Berlin Heidelberg, Springer-Verlag p.

Karamuk, M., 2011. A survey on electric vehicle powertrain systems, Electrical Machines and Power Electronics and 2011 Electromotion Joint Conference (ACEMP), 2011 International Aegean Conference on, 315-24, 8-10 Sept. 2011.

Mazman, M., Uzun, D., Kaypmaz C. ve Biçer, E., 2012. Elektrikli Araçlar İçin Enerji Depolama Çözümleri, Mühendis ve Makina, 53, 628, 21-5.

MEGEP, 2011. Motorlu Araçlar Teknolojisi Otomotiv Peryodik Bakımı, Ankara, Milli Eğitim Bakanlığı, p. 3-4.

ODD, 2014. Otomotiv Dağıtıcıları Derneği (ODD) Genel Değerlendirme: 19-20.

ODD, 2015. Otomotiv Dağıtıcıları Derneği (ODD) Genel Değerlendirme: 22-3. 
PETDER, 2014. Petrol Sanayi Derneği (PETDER) 2014 Sektör Raporu.

Polat, Ö., Yumak, K., Sezgin, M.S., Yumurtaci, G. ve Gül, Ö., 2015. Elektrikli Araç ve Şarj İstasyonlarinin Türkiye'deki Güncel Durumu, VI.Enerji Verimliliği, Kalitesi Sempozyumu ve Sergisi, Kocaeli.

Shiau, C-S.N., Samaras, C., Hauffe, R. ve Michalek, J.J., 2009. Impact of battery weight and charging patterns on the economic and environmental benefits of plug-in hybrid vehicles, Energy Policy, 37, 7, 2653-63.
Uçarol, H. ve Kural, E., 2009. Ulaşımda Enerji Verimliliği için Hibrid ve Elektrikli Araçlar, Mühendis ve Makina, 50, 594, 66-71.

URL-1, http://my.teslamotors.com / roadster / technology/motor. 25 Ağustos 2015.

URL-2, https:// tr.wikipedia.org / wiki / Elektrikli_otomobil-cite_note-49. 12 Mart 2016.

URL-3, http:// petbayder.org / sayfa / 312 / akaryakit-sektorunde-13630-lisansvar. 12 Mart 2016. 